\title{
Notes on the vocalizations of Beautiful Sunbird (Cinnyris pulchellus)
}

Peter Boesman

In the following we briefly analyze and compare voice of the two races of Beautiful Sunbird (Cinnyris pulchellus). We also try to quantify the extent of any vocal differences using the criteria proposed by Tobias et al. (2010), as a support for taxonomic review.

We have made use of sound recordings available on-line from Xeno Canto (XC).

Song is a sequence of variable twittering warbled phrases, often preceded or intermixed with series of slightly nasal staccato notes or chatters.

Some examples:

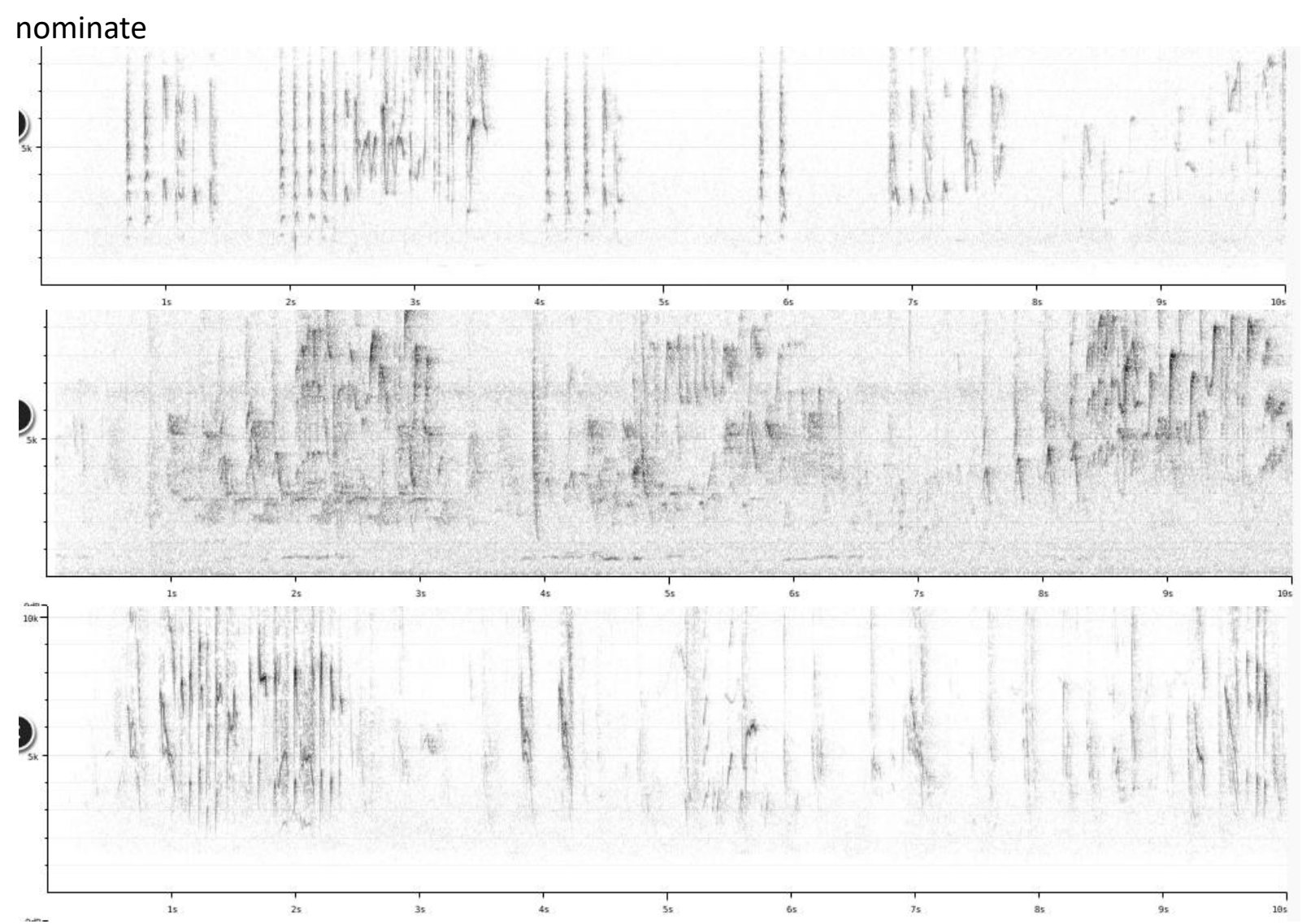



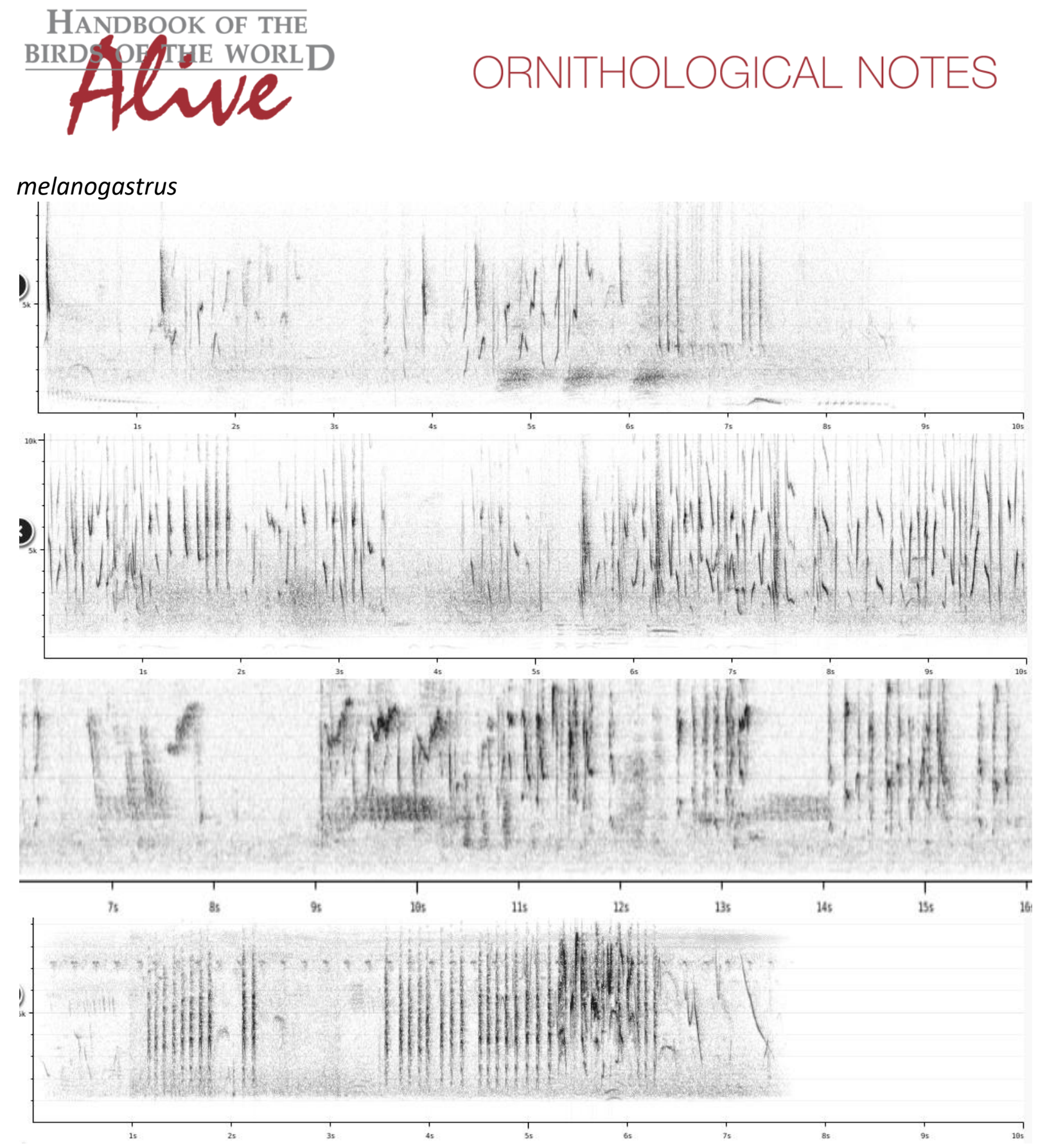

Song of both races is very similar, both in structure and in basic sound parameters (phrase length, number of notes, min./max. frequency etc.). Even note shapes look quite similar, although an in depth analysis involving many more recordings would be needed to prove this right.

We can conclude that there are no obvious vocal differences.

This note was finalized on 25th April 2016, using sound recordings available on-line at that moment. We would like to thank in particular the sound recordists who placed their recordings for this species on XC: Jason Anderson, Peter Boesman, James Bradley, Gabriel Jamie, Rory Nefdt, Bram Piot, Matt Slaymaker and Martin St-Michel. 


\section{References}

Tobias, J.A., Seddon, N., Spottiswoode, C.N., Pilgrim, J.D., Fishpool, L.D.C. \& Collar, N.J. (2010). Quantitative criteria for species delimitation. Ibis 152(4): 724-746.

\section{Recommended citation}

Boesman, P. (2016). Notes on the vocalizations of Beautiful Sunbird (Cinnyris pulchellus). HBW Alive Ornithological Note 339. In: Handbook of the Birds of the World Alive. Lynx Edicions, Barcelona. (retrieved from http://www.hbw.com/node/1252798 on 25 October 2016). 